\title{
Evaluation via Multivariate Techniques of Scale Factor Variability in the Rietveld Method Applied to Quantitative Phase Analysis with X Ray Powder Diffraction
}

\author{
Terezinha Ferreira de Oliveira ${ }^{\mathrm{a} *}$, Roberto Ribeiro de Avillez, \\ Eugenio Kahn Epprecht, Joaquim Carlos Barbosa Queiroz ${ }^{\mathrm{a}}$ \\ ${ }^{a}$ Departamento de Estatística, Universidade Federal do Pará, Campus Universitário do Guamá, \\ Rua Augusto Correa, 1, Guamá, 66075-110 Belém - PA, Brazil \\ ${ }^{\mathrm{b}}$ Departamento de Ciências de Materiais e Metalurgia, \\ Pontifícia Universidade Católica do Rio de Janeiro, \\ Rua Marquês de São Vicente, 225, Gávea, 22453-900 Rio de Janeiro - RJ, Brazil \\ 'Departamento de Engenharia Industrial, \\ Pontifícia Universidade Católica do Rio de Janeiro, Rua Marquês de São Vicente, 225, \\ Gávea, 22453-900 Rio de Janeiro, RJ - Brazil \\ 'Departamento de Estatística, Universidade Federal do Pará, \\ Campus Universitário do Guamá, Rua Augusto Correa, 1, Guamá, \\ 66075-110 Belém, PA - Brazil
}

Received: January 13, 2006; Revised: October 24, 2006

\begin{abstract}
The present work uses multivariate statistical analysis as a form of establishing the main sources of error in the Quantitative Phase Analysis (QPA) using the Rietveld method. The quantitative determination of crystalline phases using $\mathrm{x}$ ray powder diffraction is a complex measurement process whose results are influenced by several factors. Ternary mixtures of $\mathrm{Al}_{2} \mathrm{O}_{3}, \mathrm{MgO}$ and $\mathrm{NiO}$ were prepared under controlled conditions and the diffractions were obtained using the Bragg-Brentano geometric arrangement. It was possible to establish four sources of critical variations: the experimental absorption and the scale factor of $\mathrm{NiO}$, which is the phase with the greatest linear absorption coefficient of the ternary mixture; the instrumental characteristics represented by mechanical errors of the goniometer and sample displacement; the other two phases $\left(\mathrm{Al}_{2} \mathrm{O}_{3}\right.$ and $\left.\mathrm{MgO}\right)$; and the temperature and relative humidity of the air in the laboratory. The error sources excessively impair the QPA with the Rietveld method. Therefore it becomes necessary to control them during the measurement procedure.
\end{abstract}

Keywords: Quantitative Phase Analysis, Rietveld method, experiment design, multivariate statistical analysis

\section{Introduction}

\subsection{Rietveld method and Quantitative Phase Analysis (QPA)}

In $x$ ray analysis, the Rietveld method of refinement is used to calculate structural parameters from observed data (Figure 1). This method employs a point-to-point adjustment of experimental intensities of the whole pattern to the calculated intensities based on the crystalline structures (spatial groups, types of atoms and site occupancy) present in the mixture ${ }^{1}$ and it also provides the weight fractions from each crystalline phase $\mathrm{e}^{2,3}$.

In the Bragg-Brentano diffraction geometry, the sample and the detector rotate with a coupled $\theta-2 \theta^{\circ}$ angular movement and thus only the crystallite planes parallel to the sample surface satisfy the Bragg's diffraction law ${ }^{4}$. All the apertures are kept fixed and, therefore, the number of $x$ ray photons that reach the detector ( $x$ ray intensity) is the experimental quantity measured as a function of the $2 \theta$ sample position.

This intensity is the fundamental quantity for structural refinements of the experimental diffraction pattern. The calculated intensity $\mathrm{y}_{\mathrm{ci}}$ in the $\mathrm{x}$ ray powder diffraction pattern of the phase is mainly determined by the structure-factor, $\left|\mathrm{F}_{\mathrm{k}}\right|^{2}$, plus corrections due to geo- metrical effects, polarization, absorption, preferred orientation in the neighborhood of the reflection position calculated by the Bragg law, plus the background. For a single phase the intensity can be expressed by:

$$
\mathrm{y}_{\mathrm{ci}}=\mathrm{S}_{\mathrm{t}} \sum_{\mathrm{k}} \mathrm{L}_{\mathrm{Pk}}\left|\mathrm{F}_{\mathrm{k}}\right|^{2} \varphi\left(2 \theta_{\mathrm{i}}-2 \theta_{\mathrm{k}}\right) \mathrm{P}_{\mathrm{k}} \mathrm{A}+\mathrm{y}_{\mathrm{bi}}
$$

where

$\mathrm{S}_{\mathrm{t}}$ is the scale factor;

$\mathrm{k}$ is the Miller index for Bragg's reflection;

$\mathrm{L}_{\mathrm{Pk}}$ represents Lorentz-polarization correction;

$\varphi$ is the profile reflection function;

$\mathrm{P}_{\mathrm{k}}$ is the preferred orientation function;

$\mathrm{A}$ is the absorption factor;

$\mathrm{F}_{\mathrm{k}}$ is the structure-factor for k-th Bragg's reflection; and

$\mathrm{y}_{\mathrm{bi}}$ is the background intensity in the i-th interaction.

As the Rietveld method uses a whole-pattern-fitting algorithm, its application to Quantitative Phase Analysis, QPA, provides many advantages over traditional methods that utilize a small set of reflec- 


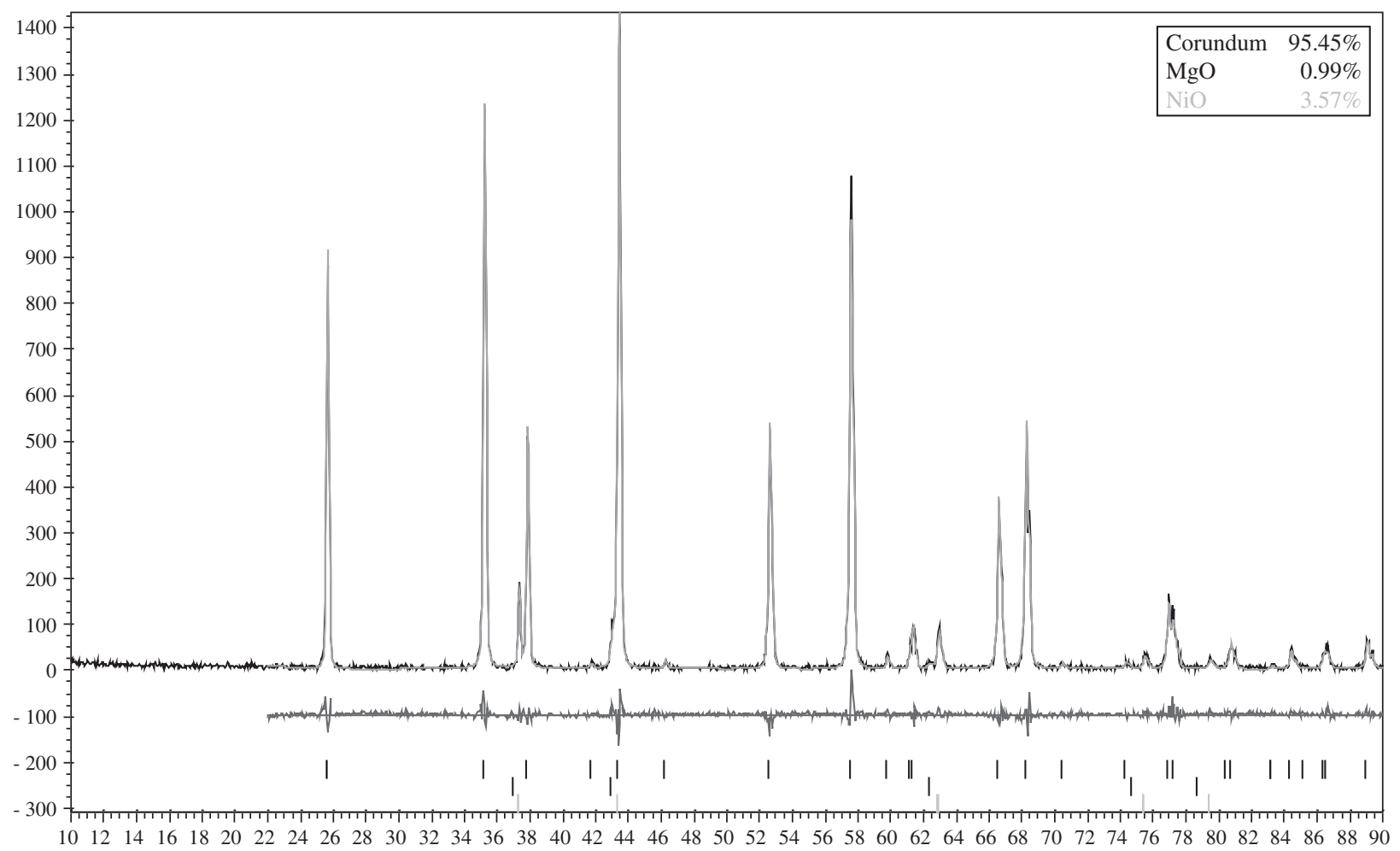

Figure 1. Rietveld refinement pattern for a mixture of $\mathrm{Al}_{2} \mathrm{O}_{3}, \mathrm{MgO}$ and $\mathrm{NiO}$ in the ratio 95.500, 0.990 and 3.510\%, respectively. The observed data are indicated by points and the calculated data by a solid line. The lower curve shows the difference between the observed and calculated powder diffraction patterns.

tion lines. This method consists in the adjustment of the experimental pattern to the whole profile, obtaining the quantitative information of phases through the scale factors, followed by the use of Equation 2 for each phase of the mixture ${ }^{2,3}$. For crystalline phase mixtures, the weight fraction of the phase $\mathrm{t}, \mathrm{w}_{\mathrm{t}}$, in a mixture of $\mathrm{n}$ phases is given by:

$$
\mathrm{W}_{\mathrm{t}}=\frac{\mathrm{S}_{\mathrm{t}}(\mathrm{ZMV})_{\mathrm{t}}}{\sum_{\mathrm{j}=1}^{\mathrm{n}} \mathrm{S}_{\mathrm{j}}(\mathrm{ZMV})_{\mathrm{j}}}
$$

where $\mathrm{Z}_{\mathrm{t}}$ is the number of molecules per unit cell, $\mathrm{M}_{\mathrm{t}}$ the molecular weight per formula unit, $\mathrm{V}_{\mathrm{t}}$ the volume of the unit cell and $\mathrm{S}_{\mathrm{t}}$ is the Rietveld scale factor.

The diffraction peak shapes can be adjusted by mathematical empirical equations or by semi-empirical descriptions of the optical geometry of the diffractometer. In the empirical adjustment, the method uses functions such as Gauss, Lorentz, Voigt, Pseudo-Voigt and Pearson VII to model the peak shape ${ }^{1}$.

The present work considers only the method of fundamental parameters proposed by Cheary and Coelho ${ }^{5}$ and available in the TOPAS 2.1 computer program ${ }^{6}$. The adjustment through fundamental parameters enables line profiles to be modelled and fitted to the observed data over the full $2 \theta^{\circ}$ range in the $\mathrm{x}$ ray diffraction pattern for a wide range of instrumental configurations. A convolution approach is used to synthesize line profiles in terms of the $\mathrm{CuK} \alpha$ emission profile, the geometry of the diffractometer and the physical variables of the specimen.

\section{Multivariate Analysis}

Multivariate statistical methods can be applied to several practical problems with the objective of measuring the effects of a large number of factors on a "response variable" or system output, or with the objective of determining the relationships among multiple variables?
The analysis of a group of data by multivariate methods can provide information concerning the structure of the measurement process. This approach has already been used in other measurement processes such as Nuclear Magnetic Resonance ${ }^{8}$.

This article analyzes the variability of the scale factor using multivariate techniques, because it is not possible to evaluate the effects of each influencing factor without considering the interactions among the several factors in Equation 1 and, consequently, in Equation 2.

In powder analysis by $\mathrm{x}$ rays diffraction, multivariate methods are already being used in phase identification, for example in pharmaceutical and industrial analyses ${ }^{9}$.

In the present work, Factor Analysis was employed to identify the correlation of the refinement parameters of the TOPAS $2.1 \mathrm{com}$ puter program and the temperature and relative humidity of the air in the laboratory.

The method used in the Factor Analysis was Principal Components Analysis (PCA), with varimax rotation, with the objective of finding a rotation of the factors that simplifies their interpretation $^{7,10}$.

\section{Materials and Method}

\subsection{Experimental design}

In order to guarantee the traceability of the measurement system, the experimental design considered three phases with established purity (BAM-Certified Reference Material): $\mathrm{Al}_{2} \mathrm{O}_{3}$ (ZRM2), $\mathrm{MgO}$ (ZRM-RS 6M) and $\mathrm{NiO}$ (ZRM-RS5).

The response variables were the errors in the estimated weight fraction of each phase, $\hat{w}_{t}$, relative to the conventional true value, $\mathrm{w}_{\mathrm{nt}}$, for different levels of variability between the weight fractions of the different phases ${ }^{11}$. 
In the decision about the number of samples to analyze, the costs of analyzing a sample, the availability of trained operators and the temperature and relative humidity of the air in the laboratory favorable to the analysis were taken into account.

The determination of the levels of each phase or fraction was based on the article of Madsen et al. ${ }^{12}$, who use a mixture model and an experimental design that enables analyzing the effects of phase weight fraction variation using few experiments ${ }^{13}$.

The complete cubic model for three components mixtures $\left(\mathrm{w}_{1}+\mathrm{w}_{2}+\mathrm{w}_{3}=1\right)$ is given by:

$$
\hat{\mathrm{w}}=\sum_{\mathrm{i}=1}^{3} \mathrm{~b}_{1} \mathrm{w}_{\mathrm{i}}+\sum_{\mathrm{i}}^{3} \sum_{\mathrm{j} j=1}^{3} \mathrm{~b}_{\mathrm{ij}} \mathrm{w}_{\mathrm{i}} \mathrm{w}_{\mathrm{j}}+\sum_{\mathrm{i}}^{3} \sum_{\mathrm{j} j \mathrm{j}}^{3} \sum_{\mathrm{k} k=1}^{3} \sum_{\mathrm{k}}^{3} \mathrm{~b}_{\mathrm{ijk}} \mathrm{w}_{\mathrm{i}} \mathrm{w}_{\mathrm{j}} \mathrm{w}_{\mathrm{k}}
$$

This model expresses how the values of the variables of interest $\hat{w}$ change with the values of three experimental factors that are being investigated.

The least possible number of experiments to estimate the coefficients of the model above is ten experiments including mixtures with two components; a modification of this special cubic model provides a total of seven experiments ${ }^{13}$.

The use of few experiments is only justified in the stage of evaluation of the robustness ${ }^{14}$ of the method in order to verify if its results are affected by small variations in the operation conditions ${ }^{15,16}$. When the analysis comes to this stage, the method is already optimized, so only few factors or interactions are significant. This is called sparsity effect and only in such cases an experiment can be projected with a minimum number of observations ${ }^{15}$.

This idea was used for the creation of groups of samples. Three sample groups were created with different degrees of variation in the weight fraction of the three constituents: Group A (highest variation): 95, 4 and 1\%, Group B (intermediate variation): 55, 30 and 15\%, and Group C (least variation): 35,33 and $32 \%$. In each group, all the permutations of the levels for the phases were considered. Group D was also created with samples of only one phase, with the objective of giving support to the analyses of peak characteristics. In agreement with the experimental design, each phase weight fraction was obtained by individually weighing the material in a Bel Engineering Mark 210 A Model analytical balance (Capacity: $100 \mathrm{mg}$ to $210 \mathrm{~g}$; division: $0.0001 \mathrm{~g}$; tare: $210 \mathrm{~g}$; reproducibility: $0.1 \mathrm{mg}$ and linearity: $\pm 0.3 \mathrm{mg}$ ). For each sample of the experimental design, three independent replicates of $1.0 \mathrm{~g}$ were prepared and mixed, adding up to a total of 63 samples.

The material was scattered over a stainless steel sample holder $2 \mathrm{~mm}$ deep according to the procedure by Klug and Alexander ${ }^{15}$.

\section{Diffractometer Calibration}

The samples were read in a Siemens D-5000 diffractometer, with a fine focus, $\operatorname{CuK} \alpha(\lambda=1.54178 \AA)$ radiation tube with graphite monochromator, Bragg-Brentano geometry, scans from 22 to $90^{\circ}$ with $2 \theta$ steps of $0.05^{\circ}$ and acquisition time of $4 \mathrm{~s}$ per step. The equipment was calibrated mechanically according to the manufacturer specifications.

\section{Computational Program and Refinement Parameters}

The computer program TOPAS 2.1 (Bruker AXS GmbH, Germany) was used for Rietveld refinement using the fundamental

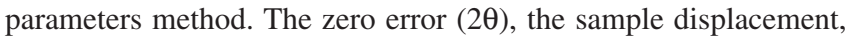
the absorption $(1 / \mathrm{cm})$ and the lattice parameters of the phases were allowed to vary to provide the best fitting. The March-Dolase model in Bruker (2003) was used for preferred-orientation correction. The background was fitted by a fifth-order Chebychev polynomial.
The results of the Rietveld adjustment, for each phase in the sample, were: the scale factor $\left(\mathrm{S}_{\mathrm{t}}\right)$, the lattice parameters, the volume of the unit cell $\left(\mathrm{V}_{\mathrm{t}}\right)$ and the weight fraction of the phase $\left(\mathrm{w}_{\mathrm{t}}\right)$.

In addition to these results, the influence quantities: temperature and relative air humidity within the radiation protection box of the goniometer were also considered as variables.

The statistical analyses were performed in the Statistical Package for Social Sciences - SPSS 10.0 for Windows ${ }^{17}$.

\section{Results}

The analyses of the data considered three replications of each experiment (treatment) in the groups A, B and C, adding up to 54 samples.

The group whose relative error presented the greatest variability was Group A (Figure 2). The relative error of each sample was obtained by the sum of the absolute values for each phase. Table 1 shows the statistics of the relative error per group. The Kruskall-Wallis test showed significant differences between the errors of the groups A, $\mathrm{B}$ and $\mathrm{C}(\mathrm{H}=13.144$ and $\mathrm{p}=0.001)$.

Table 2 shows the means and standard errors of the linear absorption coefficient, of the density and of the mass absorption coefficient for each phase. It is known that linear absorption coefficients play a decisive effect in the absorption ${ }^{18,19}$.

Table 3 presents the analysis of the Pearson correlation coefficients between the scale factors of the three phases, $S_{t}, t=1,2$ and 3 ,

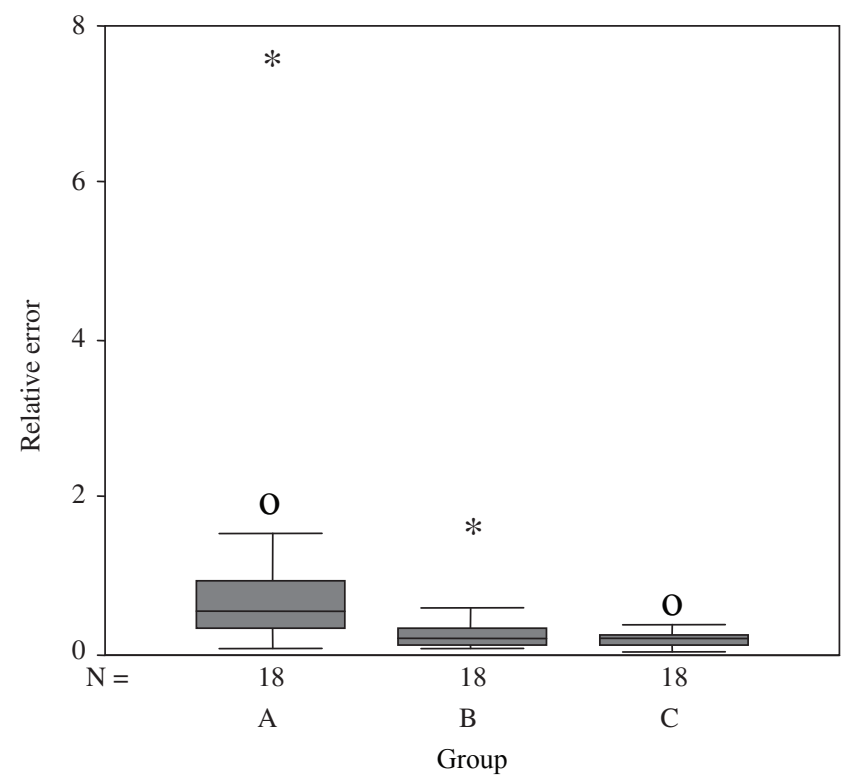

Figure 2. Box-plot of relative errors per group. The box length is the interquartile range. Outliers (values between 1.5 and 3 box lengths far from the upper or lower edge of the box) are indicated by "o" and extremes (values more than 3 box lengths far from the upper or lower edge of the box) are indicated by "**”.

Table 1. Descriptive statistics of relative error to the QPA.

\begin{tabular}{ccccc}
\hline Group & $M$-Estimate ${ }^{(1)}$ & Median & $\begin{array}{c}\text { Interquartile } \\
\text { range }\end{array}$ & $\hat{\sigma}$ \\
\hline A & 0.535 & 0.554 & 0.605 & 1.698 \\
B & 0.205 & 0.233 & 0.230 & 0.365 \\
C & 0.173 & 0.198 & 0.184 & 0.170 \\
\hline
\end{tabular}

$\mathrm{H}=13.14$ and $\mathrm{p}=0.001$

(1) Tukey's M-estimate. 
the absorption (A), the zero error of the goniometer (Zero error of $2 \theta$ ), the displacement of the sample $(\Delta)$, the relative humidity of the air (U\%) and the temperature (T).

Significant correlations can be observed in the Table 3 between the scale factors of $\mathrm{Al}_{2} \mathrm{O}_{3}$ and $\mathrm{MgO}$, and between the scale factors of $\mathrm{MgO}$ and $\mathrm{NiO}$, even though the correlation between $\mathrm{Al}_{2} \mathrm{O}_{3}$ and $\mathrm{NiO}$ is not significant.

The absorption, on the other hand, is significantly correlated with the scale factor of the $\mathrm{Al}_{2} \mathrm{O}_{3}$ and with the scale factor of the $\mathrm{NiO}$ (Table 2).

The zero error of $2 \theta$ has a very strong correlation with the sample displacement. This was already expected because the sample displacement error is corrected with a function that also alters the $2 \theta$ offset given by Klug and Alexander ${ }^{16}$ and by Cheary and Coelho ${ }^{5}$ :

$$
\mathrm{D}_{2 \theta}=\frac{(2 \Delta \cos \theta) 180^{\circ}}{\pi}
$$

where $\Delta$ is the displacement of the sample in $\mathrm{mm}$ and $\theta$ is the diffraction angle in degrees.

The correlation between the absorption and the relative humidity of the air inside the radiation protection box of the goniometer is negative.

The Factor Analysis resulted in four factors (see Table 4) representing $85.718 \%$ of the total variance, all with values greater than one and each factor representing a variance structure of the measurement process.

In the Factor Analysis, the variance of each variable can always be divided into two portions: one due to common factors and the other due to individual factors.

The variance due to the common factors is called communality ${ }^{7,10}$. The communality values in the first column of Table 4 are high, with the smallest value being equal to $68.200 \%$, for the scale factor of $\mathrm{Al}_{2} \mathrm{O}_{3}$, and the largest value being equal to $96.400 \%$, for the zero error of $2 \theta$, which means that the Factor Analysis adequately describes the variability of the process.

Indeed, the Kaiser-Meyer-Olkin measure of adherence of the model to the data ${ }^{7,10}$ was 0.664 , above 0.500 , for the complete matrix,

Table 2. Linear and mass absorption coefficients and density obtained by Rietveld refinement.

\begin{tabular}{lccc}
\hline Phase & $\begin{array}{c}\text { Linear absorption } \\
\text { coefficient }(1 / \mathrm{cm})\end{array}$ & $\begin{array}{c}\text { Mass Absorption } \\
\text { coefficient }\left(\mathrm{cm}^{2} / \mathrm{g}\right)\end{array}$ & $\begin{array}{c}\text { Density } \\
\left(\mathrm{g} / \mathrm{cm}^{3}\right)\end{array}$ \\
\hline $\mathrm{Al}_{2} \mathrm{O}_{3}$ & $126.200 \pm 0.220$ & $31.744 \pm 0.002$ & $3.976 \pm 0.008$ \\
$\mathrm{MgO}$ & $103.065 \pm 0.136$ & $28.772 \pm 0.004$ & $3.582 \pm 0.004$ \\
$\mathrm{NiO}$ & $276.292 \pm 1.682$ & $40.668 \pm 0.250$ & $6.794 \pm 0.0042$ \\
\hline
\end{tabular}

indicating the adequacy of the model, and the Bartlett's sphericity test presented a value of 718.327 for the $\chi^{2}$ with 28 degrees of freedom.

The factors are presented in Table 4 in the order of extraction, which coincides with the order of importance. In other words, the first factor, representing the absorption and the scale factor of $\mathrm{NiO}$ estimated by the Rietveld method, is the most important for the measurement process since it is responsible alone for $25.964 \%$ of the total variance of the measure. The second factor represents the zero error of $2 \theta$ and the sample displacement from the parafocal position. The third factor represents the two other phases and respective weight fractions. The fourth factor represents the temperature and relative humidity of the air in the laboratory.

\section{Discussion}

The results of the Factor Analysis allow the following inferences concerning the determined factors:

The greatest weight was given to the scale factor and the absorption associated to the $\mathrm{NiO}$, that jointly explain $25.964 \%$ of the total variance of the process. Greater absorption reduces the intensity of the peak in Equation 1. NiO has the greatest linear absorption among the three different phases, $276.292 \pm 1.682(1 / \mathrm{cm})$ (Table 2), which is about twice the values obtained for the other phases; this probably explains its major effect on the measured errors.

\subsection{Factor 2: Instrumental characteristics}

The second factor was formed by the variables that represent the $2 \theta$ zero offset of the goniometer and the displacement of the sample, which jointly explain $25.508 \%$ of the variance of the measurement

Table 4. Factors obtained by PCA with varimax rotation of the refinement parameters.

\begin{tabular}{lcrrrr}
\hline & & \multicolumn{5}{c}{ Factors } \\
\multicolumn{1}{c}{ Variable } & Communalities & \multicolumn{1}{c}{1} & \multicolumn{1}{c}{2} & \multicolumn{1}{c}{3} & \multicolumn{1}{c}{4} \\
\hline $\mathrm{SAl}_{2} \mathrm{O}_{3}$ & 0.682 & -0.391 & 0.073 & $\mathbf{- 0 . 7 2 3}$ & -0.036 \\
$\mathrm{SMgO}$ & 0.869 & -0.254 & 0.137 & $\mathbf{0 . 8 8 3}$ & 0.077 \\
$\mathrm{SNiO}$ & 0.962 & $\mathbf{0 . 9 5 1}$ & -0.119 & -0.206 & 0.023 \\
$\mathrm{~A}$ & 0.904 & $\mathbf{0 . 9 0 4}$ & 0.132 & 0.249 & -0.084 \\
$\mathrm{Z} 2 \theta$ & 0.964 & 0.020 & $\mathbf{0 . 9 7 6}$ & 0.099 & 0.026 \\
$\Delta$ & 0.944 & -0.020 & $\mathbf{0 . 9 7 1}$ & -0.023 & 0.012 \\
$\mathrm{U} \%$ & 0.782 & -0.280 & -0.173 & -0.057 & $\mathbf{0 . 8 1 9}$ \\
$\mathrm{T}$ & 0.750 & -0.243 & -0.243 & -0.185 & $\mathbf{- 0 . 7 7 4}$ \\
Variance $(\%)$ & 85.718 & 25.964 & 25.508 & 18.186 & 16.060 \\
\hline
\end{tabular}

Table 3. Correlation matrix of the scale factors, absorption, zero error of the goniometer, displacement of the sample, temperature and air relative humidity during sample reading in the diffractometer.

\begin{tabular}{|c|c|c|c|c|c|c|c|c|}
\hline & $\mathrm{S}_{\mathrm{Al}_{2} \mathrm{O}_{3}}$ & $\mathrm{~S}_{\mathrm{MgO}}$ & $\mathrm{S}_{\mathrm{NiO}}$ & A & Zero $2 \theta$ & $\Delta$ & $\mathrm{U} \%$ & $\mathrm{~T}$ \\
\hline $\mathrm{S}_{\mathrm{Al}_{2} \mathrm{O}_{3}}$ & 1.000 & - & - & - & - & - & - & \\
\hline $\mathrm{S}_{\mathrm{MgO}}$ & - 0.340 & 1.000 & - & - & - & - & - & \\
\hline $\mathrm{S}_{\mathrm{NiO}}$ & -0.235 & - 0.417 & 1.000 & - & - & - & - & \\
\hline A & - 0.407 & 0.070 & 0.776 & 1.000 & - & - & - & \\
\hline Zero $2 \theta$ & -0.056 & 0.190 & -0.118 & 0.168 & 1.000 & - & - & \\
\hline$\Delta$ & 0.014 & 0.087 & -0.109 & 0.082 & 0.937 & 1.000 & - & \\
\hline $\mathrm{U} \%$ & -0.022 & 0.013 & -0.183 & -0.331 & -0.113 & -0.083 & 1.000 & \\
\hline $\mathrm{T}$ & 0.089 & -0.249 & -0.143 & -0.214 & -0.232 & -0.160 & -0.281 & 1.000 \\
\hline
\end{tabular}

Boldface values correspond to significant correlation at the level $\alpha=5 \%$. 
process. The $2 \theta$ zero offset is due to the misalignment of the equipment with the rotational axis in the circle of the goniometer. The displacement of the sample from the parafocal condition of the goniometer may be due to an incorrect positioning of the sample holder on its support or to the incorrect level of the sample inside the sample holder. If the equipment is correctly adjusted, the misalignment of the equipment and the incorrect positioning of the sample holder are associated with the intrinsic variations of the equipment mechanics and can be regarded as systematic errors. However, the displacement caused by the incorrect level of the sample is an error associated with the preparation method. Training the operators can minimize this error.

\subsection{Factor 3: Other phases}

This third factor was formed by the variables related to $\mathrm{Al}_{2} \mathrm{O}_{3}$ and $\mathrm{MgO}$ (both with absorption coefficient per unit mass smaller than the one of $\mathrm{NiO}$ ), which jointly explain about $18.186 \%$ of the total variance of the measurement process. High negative factor loadings for $\mathrm{Al}_{2} \mathrm{O}_{3}$ can also be observed in this factor, as can be evaluated by the graphs in Figures $3 \mathrm{a}$ and $3 \mathrm{~b}$. The negative correlation between $\mathrm{Al}_{2} \mathrm{O}_{3}$ and $\mathrm{MgO}$ may be due to other influences like the high counting statistics in the region of the $\left(\begin{array}{lll}2 & 0 & 0\end{array}\right)$ reflection of the $\mathrm{MgO}$ phase, which is strongly affected by the preferred orientation and also corresponds to the strongest reflection for $\mathrm{MgO}^{11}$.

This fourth factor was formed by the variables that represent the temperature and the humidity inside the diffractometer, which jointly explain about $16.060 \%$ of the variance of the measurement process. High negative factor loadings for the temperature can also be observed. The main effect would be the adsorption of water in the sample. Even though the $\mathrm{x}$ ray absorption coefficient of water is small (light elements), the adsorption of water will alter the apparent density of the sample with effect on the absorption and hence, on the scale factor. The increase of the temperature usually causes a reduction of the amount of water adsorbed, resulting in a negative correlation.

\section{Conclusion}

The evaluation of scale factor variability by $\mathrm{x}$ ray powder diffraction based on the Rietveld method using multivariate techniques proved effective in the identification of the occurrence of variation in the measurement process, identifying the principal critical variation sources that should be considered in the QPA. The analysis has shown the importance of the linear absorption on the determination of the scale factors, which for each phase are dependent on the other phases in the mixture, and also the importance of a careful calibration of the equipment and preparation of the sample as well as the control of the environmental conditions in the laboratory.

Therefore, since the scale factors of the phases are correlated, it is necessary to use other multivariate techniques that make possible to work with orthogonal matrices ${ }^{20,21}$ e.g. Partial Least Squares (PLS), to determine how factors like absorption, instrumental characteristics and environmental conditions affect the scale factor and, as a consequence, the Quantitative Phase Analysis by the Rietveld Method.

\section{Acknowledgments}

The authors are grateful to the CNPq (Conselho Nacional do Desenvolvimento Científico e Tecnológico), the CAPES (Comissão de Aperfeiçoamento de Pessoal de Nível Superior) and the FAPERJ (Fundação de Apoio à Pesquisa do Estado do Rio de Janeiro) for the financial support, and to the BAM (Bundesanstalt für Materialforschung und -prüfung) for the material standards employed in this research.

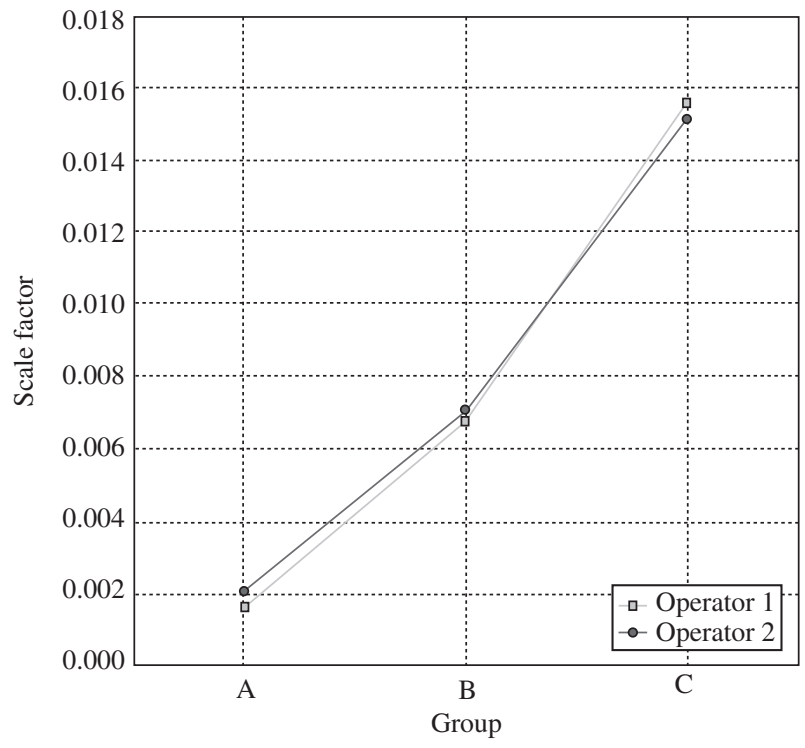

(a)

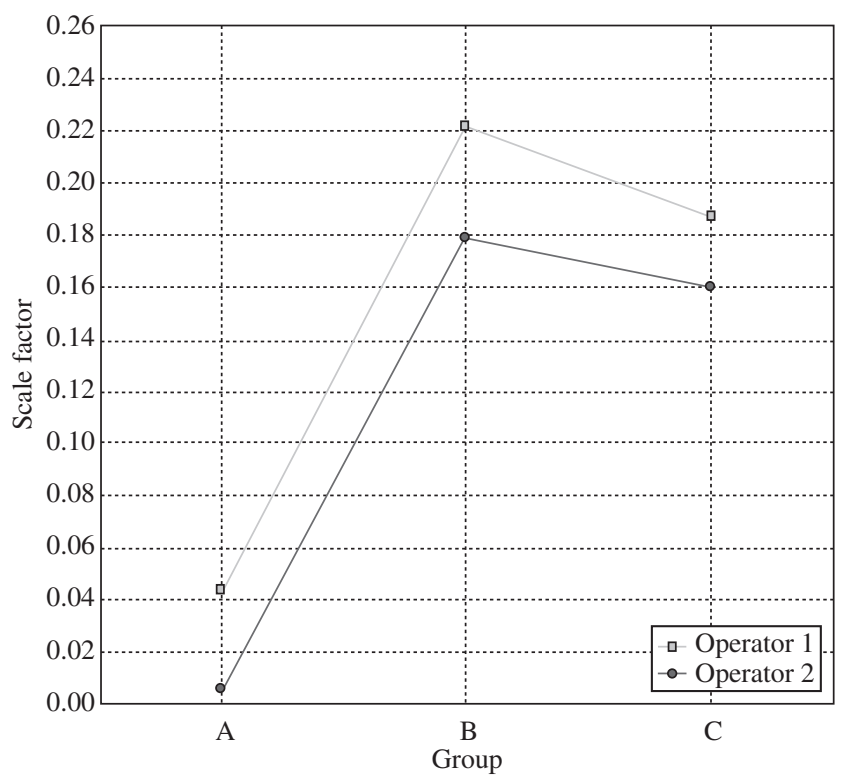

(b)

Figure 3. Scale factor of a) $\mathrm{Al}_{2} \mathrm{O}_{3}$ per groups and operators; and b) $\mathrm{MgO}$ per groups and operators.

\section{References}

1. Young R. The Rietveld Method. New York: Oxford University Press Inc.; 1995.

2. Bish L, Howard A. Quantitative Phase Analysis Using Rietveld Method. Journal of Applied Crystallography. 1988; 21(2):86-91.

3. Cullity BD. Elements of X-ray diffraction. London: Addison-Wesley Pub. Company Inc.; 1967.

4. Hill R, Howard C. Quantitative phase analysis from neutron powder diffraction data using the Rietveld Method. Journal of Applied Crystallography. 1987; 20(6):467-474.

5. Cheary R, Coelho A. A fundamental parameters approach to X-Ray lineprofile fitting. Journal of Applied Crystallography. 1992; 25(2):109-121.

6. Bruker AXS GmbH. Topas: General profile and structure analysis software for powder diffraction data. Karlsruhe; 2003.

7. Hair J, Anderson R, Tathan R, Black W. Multivariate Data Analysis. $5^{\text {th }}$. ed. New Jersey: Prentice Hall; 1998. 
8. Malinowski ER. Factor Analysis in Chemistry. New York: John Wiley; 1991.

9. Barr G, Dong W, Gilmore C. High-throughput powder diffraction. II. Applications of clustering methods and multivariate data analysis. Journal of Applied Crystallography. 2004; 37(2):243-252.

10. Johnson R, Wichern D. Applied Multivariate Statistical Analysis. London: Prentice-Hall; 1982.

11. Oliveira TF. Análise das incertezas na quantificação de fase pelo método de Rietveld em análise de pó por difração de raios $X$. [Doctoral thesis on the Internet]. Rio de Janeiro: PUC-Rio; 2005. Available from http://www. maxwell.lambda.ele.puc-rio.br

12. Madsen I, Scarlett N, Cranswick L, Lwint T. Outcomes of the International Union of Crystallography Commission on Powder Diffraction Round Robin on Quantitative Phase Analysis: samples 1a to 1h. Journal of Applied Crystallography. 2001; 34(4):409-426.

13. Barros Neto B, Scarminio I, Bruns R. Como fazer experimentos: pesquisa e desenvolvimento na ciência e na indústria. Campinas: Editora da Unicamp; 2001.

14. International Organization for Standardization. International Vocabulary of basic and general terms in Metrology. $2^{\text {nd }}$ ed. Geneva; 2003.
15. Nijhhuis A, van der Knaap H, de Jong S, Vanderginste B. Strategy for ruggedness tests in chromatographic method validation. Analytica Chimica Acta. 1999; 391(2):87-202.

16. Klug H, Alexander LE. X-Ray Diffraction Procedures. New York: John Wiley; 1974.

17. Norusis M. SPSS 11.0: Guide to Data Analysis. New Jersey: Prentice Hall; 2002.

18. Brindley G. On the Effect of Grain or Particle Size on X ray Reflections. Philosophical Magazine. 1945; 36(1):347-369

19. Taylor J, Matulis C. Absorption Contrast Effects in the Quantitative XRD Analysis of Powder by Full Multiphase Profile Refinement. Journal of Applied Crystallography. 1991; 24(1):14-17.

20. Sena M, Collins C, Collins K, Scarmino I. Aplicação de Métodos Quimiométricos na Especiação de Cromo(VI) em Solução Aquosa. Química Nova. 2001; 24(3):331-338.

21. Valderra P. Avaliação de figuras de mérito em calibração multivariada na determinação de parâmetros de controle de qualidade em indústria alcooleira por espectrometria no infravermelho próximo. [Master thesis on the internet]. São Paulo: UNICAMP; 2005 [cited 2005Oct27]. Available from http://biq.iqm.unicamp.br/arquivos/teses/ficha66444.htm 